\title{
Psychiatric diagnosis in legal settings
}

\author{
Alfred Allan, BCom, BA Hons, LLB, MA, PhD \\ Clinical Forensic Psychology Program, Edith Cowan \\ University, Perth, Western Australia
}

When asked to give a diagnosis in legal settings practitioners should be mindful of the tentative nature of psychiatric diagnoses and that courts require that such a diagnosis must have scientific credibility. South African courts are not explicit about the test they will apply to determine whether a diagnosis is scientifically credible, but some guidance can be found in United States case law. This paper examines these criteria with reference to the disorders included in the Diagnostic and Statistical Manual of Mental Disorders (DSM-IV-TR).

Since diagnostic labels form an integral part of mental health research and practice it is unavoidable that they will be used in court. They are mostly used as labels that encapsulate the signs observed by, and symptoms reported to, a practitioner. However, a diagnosis can also be offered in the course of an explanation of behaviour. This would be the case where a practitioner refers to a diagnostic label (usually trauma related) while explaining the counter-intuitive behaviour of a person. For example, to explain the reluctance of a trauma victim to discuss the traumatic incident the practitioner may testify that this is often found with people who meet the criteria of an acute stress disorder. Finally, and more problematically, a lawyer may try to prove that a trauma took place or not, by demonstrating the presence or absence of the symptoms of a disorder.

Whatever the context, various aspects of testifying on the basis of diagnostic labels in court are controversial. Some believe practitioners should not be allowed to give a diagnosis at all; $i^{1-4}$ others question the use of so-called syndrome evidence (i.e. syndromes that have not been included in a diagnostic manual); 5,6 while others, including the editors of the Diagnostic and Statistical Manual of Mental Disorders (DSM-IV-TR), are concerned about the manner in which diagnoses are used in legal settings. ${ }^{8.10}$

These reservations are not surprising as psychiatric disorders, even those included in the DSM-IV-TR, are tentative constructs.
They are syndromes and therefore, by definition, differ from diseases in that their aetiology is unknown or poorly understood. ${ }^{11} 16$ They are always subject to further investigation and the acquisition of new information. While this does not diminish the valuable role that diagnostic labels play in research and practice, it does mean that legal tribunals should approach psychiatric diagnoses with caution.

The admissibility and weight given by legal tribunals to scientific evidence are regulated by the rules of expert testimony, one of which is that the diagnosis given to the court must have scientific credibility.

While South African courts have not been explicit on how they determine the credibility of scientific evidence they generally appear to apply the test that was formulated in Frye $v$. United States. ${ }^{17}$ This judgment regards evidence on a scientific construct admissible if it has gained general acceptance in the particular field in which it belongs. More recently in Daubert v. Merrell Dow Pharmaceuticals ${ }^{18}$ the United States Supreme Court stipulated that a court should also take three other factors into account. First, whether the construct can be, and has been, tested; second, whether it has been subjected to peer review and publication; and finally, the known or potential rate of error.

The Daubert test has not been discussed in a reported case in South Africa, ${ }^{19}$ yet it provides practitioners with a useful framework to evaluate the scientific credibility of a diagnostic label. This paper will outline and discuss, with reference to the DSM-IV-TR, the use of this framework to establish the scientific credibility of a diagnostic label before it is used in a court.

\section{General acceptance}

Courts are not research laboratories ${ }^{20}$ and they should not, except in exceptional circumstances, consider evidence on a phenomenon that has not gained face validity, i.e. general acceptance among practitioners. It could be argued that inclusion of a diagnosis in one or both of the DSM-IV-TR and the ICD-10classification of mental and behavioural disorders indicates general acceptance. For example, the DSM-IV-TR is the product of an extensive systematic re-examination of disorders that involved more than 
1000 people and numerous professional organisations that represented diverse clinical and research backgrounds, disciplines, expertise and settings. Disorders were included on the basis of sufficient documented empirical evidence of an agreement among practitioners that a distinct disorder could be recognised. ${ }^{8}$

While this agreement is based on expert consensus rather than empirical data in the form of survey results, ${ }^{22}$ the experts involved represent a broad range of opinions and suggest general agreement.

Nevertheless, although they are widely accepted, not all the disorders included in the DSM-IV-TR are universally accepted; ${ }^{23}$ indeed, some of them are controversial. Given the ongoing expansion of knowledge it is understandable that the disorders included in it will have achieved different stages of scientific evolution. ${ }^{8}$ In fact, all of the disorders in DSM-IV-TR are still under investigation and criteria are amended as more and/or new knowledge is gained about a specific disorder. Consequently the diagnostic criteria are very likely to differ in successive editions of the manual.

This inherent tentativeness of the DSM-IV-TR is unavoidable, but it does diminish the utility of the instrument in forensic settings as the editors thereof acknowledge.

\section{Peer review and publication}

While peer review and publication are neither essential nor necessarily indicative of the scientific credibility of a diagnosis, courts should take this into account. When reviewing publications practitioners must always consider arguments contrary to their own belief about the existence of the disorder and its scientific credibility. Some specific questions that a practitioner should ask during the review of the literature will be discussed below.

\section{Testing and error rate}

The third indicator of scientific credibility is whether the construct can be or has been tested. In psychiatric terms this refers to validity (in particular descriptive, diagnostic and predictive), reliability, causal relationships and treatment efficacy of a diagnosis.

\section{Descriptive validity}

The descriptive validity of a diagnosis is considered good when its characteristics are so unique and well defined that it can be distinguished from other disorders. It is clear that the distinguishing criteria of a disorder could become very important where witnesses disagree on the correct diagnosis.
Good descriptive validity requires five things. First, that the features of the disorder are well delineated, unambiguously and accurately described, and operationally defined. This requires that there should be an indication of the duration, frequency and severity of signs and symptoms that must be met before a specific diagnosis can be made. Second, there must be a clear indication regarding how the information on each of these features should be weighted and integrated. Third, diagnostic criteria should provide explicit rules about what to do when information is insufficient or if other uncertainties exist. Fourth, the diagnosis should as far as possible rely on observable signs, or the results from reliable laboratory or psychological tests, rather than be inferred from symptoms and other subjective reports provided by the patient. Finally, there should ideally be enough signs and symptoms unique to the specific disorder to make it distinct from other disorders or diseases.

The editors of the DSM-IV-TR provide such information with regard to most of the disorders included in it, but unfortunately do not indicate what exact weights should be given to different criteria and how the information regarding the different criteria should be integrated. Changes made to accommodate new findings also negate much of the advantage of having explicit definitions of diagnostic criteria.

\section{Diagnostic validity}

The diagnostic validity or accuracy of a diagnosis refers to the probability that the diagnosis made by a practitioner is correct. This may, for example, be an issue in a case where the presence of specific mental disorders is a threshold requirement, such as in the case of criminal responsibility where the impairment must be due to a mental disorder.

The problem is that it is difficult to generate data on the diagnostic accuracy of most psychiatric disorders because of a lack of external validating criteria for comparison. Unlike diseases in general medicine, psychiatric disorders seldom have objective criteria such as biological markers, pathology results or postmortem findings that can confirm the diagnosis. Quite appropriately the editors of the manual therefore warn that generally the diagnosis of a DSM-IV-TR mental disorder is insufficient to establish the existence of a mental disorder for legal purposes. As a general rule the detailed and objective diagnostic criteria of the DSM-IV-TR and the explicit guidance regarding the procedure to follow if the information is insufficient, or if other uncertainties exist, should ensure a fair degree of diagnostic validity.

As the DSM-IV-TR does not provide information on the diagnostic accuracy of the different disorders a literature review will be 
required to establish whether studies have been done with regard to specific disorders.

While the results regarding the disorders vary, one disorder in particular, namely post-traumatic stress disorder, has poor diagnostic validity and has a tendency to be overdiagnosed by practitioners. ${ }^{24,25}$ A task force of the American Psychiatric Association singled out this diagnosis as especially prone to legal misuse. ${ }^{8}$ Halleck et al. ${ }^{8}$ suggest that the diagnostic validity of this disorder is poor because it is diagnosed largely on the basis of self-reported symptoms and the acceptance of the patient's allegation that a specific stressful event caused them. Practitioners are not required to determine whether the stressful event really happened, but can accept the perception of the patient. Practitioners should therefore be very cautious before making this diagnosis for legal purposes.

\section{Predictive validity}

Predictive validity is relevant in a case where there are issues surrounding the clinical course of the disorder and the expected response to treatment. In particular this may be the case in compensation claims, or where a person is considered to be incompetent to stand trial or undertake some legal action, and the question is whether the situation will change. The DSM-IV-TR does not provide any information regarding the prognostic accuracy of the classified disorders and a literature review is required to determine this where relevant.

\section{Diagnostic reliability}

Diagnostic reliability refers to consistency at two levels. At the first level it refers to what will be called inter-practitioner reliability, i.e. the probability that different practitioners, if presented with the same data independently, would agree on the specific diagnosis for the relevant person. At the second level it refers to the consistency with which the person receives the same diagnosis over time.

While the inter-practitioner reliability of disorders has been considered, and is adequate, ${ }^{12}$ the DSM-IV-TR does not routinely provide data in respect of the diagnostic reliability of disorders ${ }^{23}$ and a thorough literature review will be necessary to identify relevant data. A cursory review $22 \cdot 24,26,27$ suggests that the diagnostic reliability of a number of disorders is not particularly good, although there may be exceptions where, for example, practitioners work closely together and share common assumptions. ${ }^{23}$

A factor that may negatively influence the diagnostic reliability of the DSM-IV-TR disorders is the fact that practitioners are encour- aged to use diagnostic criteria 'as guidelines to be informed by clinical judgement'. However, clinical judgement is often flawed. ${ }^{23}$ A complicating factor is that practitioners rely more on behavioural signs than their colleagues in other areas. Therefore different practitioners who evaluate the same person may observe different sets of behaviour as people behave differently across time, in different settings and when dealing with people of different gender, age, race or culture. To improve inter-practitioner accuracy when doing forensic evaluations, practitioners should preferably use an instrument such as the Structured Clinical Interview for DSM-IV Axis I disorders (SCID). ${ }^{28}$

\section{Causal relationship}

Strictly speaking questions about the aetiology of psychiatric disorders should not arise in court because their cause is, by definition, unknown or poorly understood. The DSM-IV-TR is also neutral with regard to theories of aetiology. No causes are stated and the editors warn that a diagnosis does not carry any necessary implications regarding the causes of the individual's mental disorder or its associated impairments. It is also known that the presence of a certain potential cause (e.g. a trauma) does not always lead to the manifestation of a disorder (e.g. post-traumatic stress disorder). ${ }^{24}$ Even a strong relationship between a possible cause and a disorder is inconclusive and does not prove that there is a causal relationship in a specific instance.

Practitioners should therefore be very cautious when they respond to any question about the possible cause of the disorder they diagnosed, especially when lawyers try to prove that an event took place or not. This is typically done with regard to phenomena such as battered woman syndrome; ${ }^{29}$ rape trauma syndrome; ${ }^{30}$ child sexual abuse accommodation syndrome; ${ }^{31}$ and parental alienation syndrome. ${ }^{32}$ The classic case is where a lawyer uses a reverse logic argument claiming that the diagnosis of one of these syndromes substantiates a complainant's allegation that a traumatic event took place. What lawyers are essentially asking practitioners to do here is to say that the complainant is telling the truth about the cause of the reported symptoms, something that South African courts do not allow. ${ }^{33}$ The alternative argument, that a traumatic event did not take place because of the absence of a disorder, is equally unsustainable.

\section{Treatment efficacy}

Once a court has decided that a person meets the criteria for a specific disorder it will often be important to determine the form and efficacy of available treatments. Traditionally a clinical trial is used to test a treatment's efficacy. 
The DSM-IV-TR does not provide any information on different types of treatment or their treatment efficacy and information in this regard must be found in the literature.

\section{Methodology underlying the relevant research}

A final issue to consider in assessing the scientific credibility of a diagnosis is the methodology used to obtain the relevant data. While no study will ever be without limitations the samples used should, where ethically and practically possible, be representative, large enough to justify the conclusion the researcher makes, a control group should be used in treatment studies, and the participants should be randomly assigned to experimental and control groups.

A rough indicator that a study was rigorous is that it has been published in a reputable peer-reviewed source. However, even with regard to such research it is still necessary to examine the research methodology critically.

\section{Conclusion}

In view of the tentative nature of psychiatric disorders it is imperative that practitioners remind themselves and lawyers that diagnostic constructs should be used with caution in legal settings, preferably only if the diagnosis satisfies the legal perception of scientific credibility. This means that at the very least the witness must be able to demonstrate that the disorder is generally accepted as evidenced by its inclusion in a diagnostic manual and/or published peer reviews. Even then a diagnosis should only be given if the required diagnostic criteria are present. A competent witness should also have data on the other indicators of scientific credibility that may also be relevant depending on the specific issues contested in the case.

If these criteria are met a practitioner will normally be able to use a diagnosis as a descriptive label in court, and courts are generally also prepared to allow testimony that certain behaviour is commonly found among people suffering from a specific disorder. However, any opinion on the cause of a disorder should be expressed with caution.

The author wishes to acknowledge Dr Michelle Gobetz's contribution to this paper as research assistant, and Drs Maria Allan and Greg Dear and Professor Dan Stein for their comments on earlier versions of this paper.

\section{References}

1. Ennis BJ, Litwack TR. Psychiatry and he presumption of expertise: Flipping coins in he courtroom. California Law Review 1974; 62: $693-752$

2. Faust D, Ziskin J. The expert witness in psychology and psychiatry. Science 1988; 241: $31-35$.

3. Morse SJ. Law and the mental health profession: The limits of expertise. Professional Psychology 1978; 9: 389-399

4. Morse SJ. The misbegotten marriage of soft psychology and bad law. Law and Human Behavior 1990; 14: 595-618.

5. Ewing CP. Psychological self-defense: A proposed justification for battered women who kill. Law and Human Behavior 1990; 14: 579-594.

6. Fischer K. Defining the boundaries of admissible expert psychological testimony on rape trauma syndrome. University of Illinois Law Review 1989: 3: $691-734$

7. American Psychiatric Association. Diagnostic and Statistical Manual of Mental Disorders. 4 h-TR ed. Washington: APA, 2000.

8. Halleck SL, Hoge SK, Miller RD, Sadoff RL, Halleck NH. The use of psychiatric diagnoses in the legal process: Task force report of the American Psychiatric Association. Bulletin of the American Academy of Psychiatry and Law 1992; 20: 481-499

9. Nicholas L, Coleridge L. Expert witness testimony in he criminal trial of Eugene de Kock: A critique of he post traumatic stress disorder (PTSD) defence. South African Journal of Psychology 2000; 30: 33-37.

10. Shuman DW. The Diagnostic and Statistical Manual of Mental Disorders in he Courts. Bulletin of the American Academy of Psychiatry and the Law 1989; 17: 25 32

11. Hastin Bennett A, Brown J. Pears Medical Encyclopedia. London: Sphere Books, 1991.

12. Hayes SC, Follette WC. Can functional analysis provide a substitute for syndromal classification? Behavioral Assessment 1992; 14: $345-365$

13. Macpherson G, ed. Black's Medical Dictionary. $39 \mathrm{~h}$ ed. London: A and C Black, 1999.

14. Martin EA, ed. Oxford Concise Medical Dictionary. 6th ed. Oxford: Oxford University Press, 2002

15. Pugh MB, ed. Stedman's Medical Dictionary. 27th ed. Philadelphia: Lippincott, Williams and Wilkins, 2000

16. Taylor EJ, ed. Dorland's Illustrated Medical Dictionary. 27th ed. Philadelphia: WB Saunders, 1988.

17. Frye v. United States 293 F 1013 (DC Cir, 1923).

18. Daubert v. Merrell Dow Pharmaceuticals 951 F2d 1128 (9th Cir, 1993).

19. Meinties-Van der Walt L. Expert Evidence in the Criminal Justice Process: A Comparative Perspective. Amsterdam: Rozenberg Publishers, 2001

20. US v. Brown 557 F2d 541 (6th Cir, 1977).

21. World Heal h Organization. The ICD-10 Classification of Mental and Behavioura Disorders: Clinical Descriptions and Diagnostic Guidelines. Geneva: WHO, 1992.

22. Von Talge J. Overcoming courtroom challenges to he DSM-IV. Part II: Preparing for and overcoming courtroom challenges to DSM IV. American Journal of Forensic Psychology 1995; 13: 49-59.

23. Campbell TW. Challenging the evidentiary reliability of DSM-IV. American Journal of Forensic Psychology 1999; 17: 47-68

24. Rosen G. The Aleutian Enterprise sinking and post traumatic stress disorder: Misdiagnosis in clinical and forensic settings. Professional Psychology: Research and Practice 1995; 26: 82-87

25. Sparr LF, Atkinson RM. Posttraumatic stress disorder as an insanity defense: Medicolegal quicksand. Am J Psychiatry 1986; 143: 608-621.

26. Drake RE, Vaillant GE. A validity study of Axis II of the DSM-III. Am J Psychiatry 1985 142: $553-558$.

27. Lieberman $P, B a k e r F$. The reliability of psychiatric diagnosis in an emergency room Hospital and Community Psychiatry 1985; 36: 291-293.

28. First MB, Spitzer RL, Gibbon M, Williams JBW. Structured clinical interview for DSMIV Axis I disorders. Washington DC: APA 1997

29. Walker LEA. The Battered Woman Syndrome. New York: Springer; 1984

30. Burgess AW, Holstrom LL. Rape trauma syndrome. Am J Psychiatry 1974; 131: 981 $-985$

31. Summit RC. The child sexual abuse accommodation syndrome. Child Abuse Negl 1983: 7: 177-193

32. Gardner RA. The Parental Alienation Syndrome. 2nd ed. CressKill, NJ: Creative Therapeutics; 1998

33. Holtzhauzen v. Roodt 19974 SA 766 (W) 